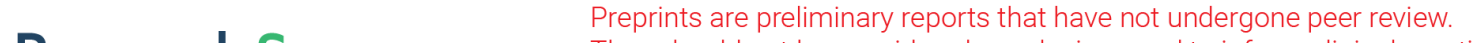 \\ They should not be considered conclusive, used to inform clinical practice, \\ or referenced by the media as validated information. \\ New Classification for Bifurcated Mandibular Neural Canal
}

\section{Hao Yang}

Central South University Xiangya Stomatological Hospital

\section{Yue Wu}

Central South University Xiangya Stomatological Hospital

\section{Pengyu Hong}

Central South University Xiangya Stomatological Hospital

\section{Yanjia Hu}

Central South University Xiangya Stomatological Hospital

\section{Zhangui Tang}

Central South University Xiangya Stomatological Hospital

\section{Kun Li (D 406889138@qq.com )}

Central South University Xiangya Stomatological Hospital https://orcid.org/0000-0002-5924-4937

\section{Research article}

Keywords: BMC, Classification, CBCT

Posted Date: December 30th, 2019

DOl: https://doi.org/10.21203/rs.2.19721/v1

License: (c) (1) This work is licensed under a Creative Commons Attribution 4.0 International License. Read Full License 


\section{New Classification for Bifurcated Mandibular Neural Canal}

\section{Hao Yang, Yue Wu, Pengyu Hong, Yanjia Hu, Zhangui Tang, Kun Li*}

Department of Oral \& Maxillofacial Surgery, Xiangya Stomatological Hospital \& School of Stomatology, Central South University, Changsha,

China

\section{Details of all authors:}

Yang Hao, M.M, Resident: cosplaydo@sina.com

Wu Yue, M.M, Resident: 1067701404@qq.com

Hong Pengyu, M.M, Resident: hpy_0713@163.com

Hu Yanjia, M.D, D.D.S, Associate Professor: 17027301@qq.com

Tang Zhangui, M.D, D.D.S, Ph.D, Professor, Department Head: tangzhangui@aliyun.com

Li Kun, M.D, D.D.S, Associate Professor: 406889138@qq.com

*Corresponding Author: Mailing address: Department of Oral \& Maxillofacial Surgery, Xiangya Stomatological Hospital \& School of

Stomatology, Central South University, Changsha 410008, Hunan, China. Tel./Fax: +86-731-84812058; E-mail: 406889138@qq.com 


\section{New Classification for Bifurcated Mandibular Neural Canal}

\section{ABSTRACT:}

Background: To analyze the occurrence rate of bifurcated neural canal (BMC) by cone beam $\mathrm{CT}(\mathrm{CBCT})$ and summarise a new classification for further clinical work and academic communication.

Method: Randomly collected the CBCT images of 350 patients (700 sides of mandibular). Firstly, we analysed and summarized the BMCs into four types. Then we have measured three kinds of distance of Type I and Type II: 1.the vertical distance between the apical foramen of molars (the second and third molar) and mandibular canal; 2. between the bifurcated site to those two molars' apical foramen; 3. between the retromolar foramen and two molars' apical foramen. At last, we compared the advantages and disadvantages about different classifications.

Results: Among these 350 patients, we found 110 people with BMC which indicated the occurrence rate of BMC was $31.43 \%$. The most common type was Type I, especially Type $\mathrm{I}_{\mathrm{B}}$, and the least was Type III. Vertical distance between the apex of the second molar, the third molar and mandibular canal are $4.36 \pm 2.51 \mathrm{~mm}$ and $2.45 \pm 2.23 \mathrm{~mm}$. Distance from the apex of two molars to the bifurcated spot are $15.87 \pm 6.82 \mathrm{~mm}$ and $9.32 \pm 5.37 \mathrm{~mm}$. And the distance between the apex and retromolar foramen in Type I are $22.19 \pm 5.97 \mathrm{~mm}$ and $15.82 \pm 4.68 \mathrm{~mm}$.

Conclusion: Comparing with former typing theory, we summarized a new classification which is more convenient and simpler for clinical implication, which should attach scholars attention to BMC during clinical work.

Key words: BMC, Classification, CBCT 


\section{Background}

In our dental clinical work, some patients have bleeding of unknown etiology, or neural symptoms of the mandibular nerve after alveolus surgeries, implantation, or sagittal split ramus osteotomy/bilateral sagittal split ramus osteotomy (SSRO/BSSRO). In exploring the causes of these symptoms, many scholars have found that the mandibular nerve canal has variations at different positions, rather than being a single canal.

Conventional theory described the mandibular canal (MC) as a cortical bone canal located between the cancellous bone of the mandible that travels inferoanteriorly in the mandibular ramus and almost horizontally forward in the body[1]. The small duct can stretch into each alveoli, providing a passage for the inferior alveolar nerve and vessels. The MC is divided into two parts at the mental foramen areas: the thicker one will become mental canal, and the thinner one will continue to form the incisive canal. Significant nerves and vessels run throughout both of them[24]. Traditional views also point that $\mathrm{MC}$ is a single canal at mandible without branches. However, a large number of scholar state bifid and even trifid mandibular canals in their related work depending on the progressive radiologic technology [5-12].

After these reports, more scholars have found it important to use other methods to research the variation of the mandibular canal, such as autopsy, histopathology, and imaging modalities [e.g., panoramic radiographs, cone beam computed tomography (CBCT), and spiral CT] $[5$, 1214]. According to the results of the methods used, it has been confirmed that the mandibular canals are myelinated nerves, veins, and arterioles. The earliest scholars used panoramic radiographs to observe the variation, which indicated that the occurrence rate of variation was $0.038 \%$ to $1.98 \%[12,15-18]$. With the widespread use of CBCT, a considerable number of scholars take advantage of the three-dimensional (3D) imaging to observe these variations more directly, making the occurrence rate as high as $10.2 \%$ to $66.5 \%[5,13,19-21]$. 
These values were sufficient to demonstrate that the bifurcated mandibular canal is not unusual. Zhang [22]made a research about bifid variations of the mandibular canal of 1000 Northern Chinese patients by CBCT, which provide a more appropriately imagological way to do research on the anatomical variation of mandibular canal. Some researchers pointed out some theory of classifications about BMC among some their features and observation methods: Nortje[23], R.P. Langlais et al[24]made correlative work by panoramic radiographs; Naitoh's theory by using CBCT to classify the bifid mandibular canals was more widely accepted [21]. Compared with the former inspection methods, CBCT give us more accurate way to study BMC. However, all these common theories are qualitative, which are limited by development of radiology and lack of specific evidence for clinical work.

As a result, we aimed to perform a research study on the structural variation of the mandibular neural canal by CBCT and, thus, pointed a constant symbol for classification and summed up a more comprehensive, yet simple, quantitative and practical typing theory for the bifurcated mandibular canals, to make clinical work and academic communication easier.

\section{Method}

\subsection{Material}

The CBCT data of 350 patients aged 18 to 70 years were randomly collected from the Xiangya Stomatological Hospital of Central South University between December 2012 and July 2017. Written informed consent was obtained from each participant. The study was approved by the Ethical Committee of Xiangya Stomatological Hospital of Central South University, approval number 20190034.

\section{Setting}


Given the low prevalence of head and neck cancers which involve the skull base, we set:

(1) Inclusion criteria:

a. Patients 18 to 70 years of age with complete images of the mandibular canal from the mandibular foramen to the mental foramen.

b. The mandible is integrated without obvious absorption, and the direction of the mandibular canal is not affected by the fracture line.

c. The image of mandibular foramen is intact and clear.

(2) Exclusion criteria:

a. $\mathrm{CBCT}$ image is blurred or there is interference in the observation area.

b. Mandible lesions (e.g., cyst, tumor, infection, severe osteoporosis) and other lesions that can obstruct observation.

c. After mandibular surgery, as the fracture line affects the direction of the mandibular canal, segmental resection, and SSRO.

\subsection{Method}

CBCT scanning: All the images used in this study were collected by the same CBCT scanner (PLANMECA), and all patients were imaged according to the standard process. Finally, the image data were stored in the PLANMECA Romexis software system. 
Reading images: In a quiet workspace, well-trained researchers adjusted the contrast images with software to make the bone structure clear and easy to define. Images were read twice with a 3-week interval between readings.

The second reading process was somewhat different: the researchers adjusted the sagittal images to make the lower edge of the mandible parallel to ground, then: (1) a horizontal line was made parallel to the lower edge of the mandible (Fig. 1, grey line); (2) a tangent line was made along with the front edge of the mandibular ramus (Fig. 1, green line), which intersects with the upper edge of the mandibular body (Fig. 1, red circle); (3) a line across the intersection was made vertical to the line in (1) (Fig. 1, yellow line). We defined the following: the bifurcation that appears in front of this vertical line (yellow line) is classified into mandibular body area, whereas the bifurcation that appears behind it is the mandibular ramus area (Fig. 1). The classification of each type depends on the starting point of the bifurcation. Details are provided in Table 1.

Depending on our classification, then we have used the former software system to measure three kinds of distance of Type I and Type II: 1.the vertical distance between the apical foramen of molars (the second and third molar) and mandibular canal; 2 . between the bifurcated site to those two molars' apical foramen; 3. between the retromolar foramen and two molars' apical foramen. All data were analyzed using Statistical Package for Social Sciences 24 (SPSS 24) for Windows.

\section{Result}

\subsection{New classification of BMC}


According to our rules, we divided BMC into for types. Type $\mathrm{I}_{\mathrm{A}}$ was bifurcations at the mandibular ramus, and retromolar foramen has been formed. Type $\mathrm{I}_{\mathrm{B}}$ was bifurcations at the mandibular ramus, and retromolar foramen has not been formed. We took those bifurcations at mandibular body as Type II. Type III was for bifurcations exist both at the mandibular body and the mandibular ramus on one side. Type IV for other circumstances. Details as following in Table1 and Fig.2

*Note 1: If there are several branches at one side of the mandibular ramus at the same time, we add total numbers before the type and specific amount of subclass on the bottom right (e.g., $2 \mathrm{I}_{\mathrm{A}}, 3 \mathrm{IA}_{2} \mathrm{~B}_{1}$ ). If the bifurcation point is exactly on the boundary of the body and ramus, we identify it as Type I.

*Note 2: If there are several branches, the number before the type represents the total amount, and the label at the top right shows the number of branches at the mandibular ramus; the label at the bottom right shows the number of branches at the mandibular body $\left(\mathrm{e} . \mathrm{g} ., \mathrm{IIII}_{\mathrm{III}}^{2 \mathrm{~A}}, 4 \mathrm{III}{ }_{2 \mathrm{IV}}^{2 \mathrm{IV}}\right)$.

\subsection{Incidence rate of $B M C$}

Among the 350 patients in our study (120 males and 230 females), we found 110 patients with BMC, for an occurrence rate of $31.43 \%$. Of these, 32 were males (26.67\%) and 78 were females (33.91\%) (Tab.2.1). Besides, we also summed up the amount of different position, and the appearance of unilateral or bilateral BMCs. According to the result of $\chi^{2}$ test, there was no statistically significant difference (Tab $2.1 \mathrm{p}=$ $0.183>0.05$, Tab2.2 $\mathrm{p}=0.097>0.05$, Tab $2.3 \mathrm{p}=0.562>0.05$ ). From all 700 sides of mandible, bifurcations occurred on 133 sides, as follows: 103 sides of Type I (14.71\%)； 27 sides of $\mathrm{I}_{\mathrm{A}}(3.86 \%)$ and 76 sides of $\mathrm{I}_{\mathrm{B}}(10.86 \%) ; 18$ sides of Type II（2.57\%）; 5 sides of Type III $(0.71 \%)$; and 7 sides of Type IV (1.00\%) (Tab.3). As shown in Table 2, Yes indicates a mandibular canal with bifurcations; No indicates a 
mandibular canal without bifurcations. As the result we can conclude that Type $\mathrm{I}$ is the most common one and $\mathrm{I}_{\mathrm{B}}$ for the subtype which can remind that we need to pay more attention on the bifurcation happened at mandibular ramus in our clinical work.

\subsection{The distance between apex of molars and mandibular canal}

In our study, we measured the distance between apex of that two molars and BMCs. The second and third molar are closely related to oral maxillofacial surgery and implant surgery. Besides, these two molars are adjoined with the spot we formulated. In Table 4, we recorded the vertical distance between the apex of the second molar, the third molar and mandibular canal are $4.36 \pm 2.51 \mathrm{~mm}$ and $2.45 \pm 2.23 \mathrm{~mm}$. The distance from the apex of the second molar, the third molar to the bifurcated spot are $15.87 \pm 6.82 \mathrm{~mm}$ and $9.32 \pm 5.37 \mathrm{~mm}$. And, the distance between the apex of the second molar, the third molar and retromolar foramen in Type I are $22.19 \pm 5.97 \mathrm{~mm}$ and $15.82 \pm 4.68 \mathrm{~mm}$. Because of the loss of the third molar, it results in the difference in the amount of samples. We should operate in this safe range of distance to avoid damaging mandibular nerves and vessels.

\subsection{Difference between four theories}

Details in Table 5.

\section{Discussion}

\subsection{Difference between the classification theories}


In nowadays, the most commonly admitted definition of BMC is to find the triangular "osseous inland" which is formed by the intersection of two pipes in panoramic radiographs and the vertex of the triangle is the starting point of the bifurcation of the mandibular canal. As early as 1977 , Nortje et al. classified BMC according to the position of the bifurcations in the mandibular body[23], this is the method that is earlier and more classic, laying the foundation for the follow-up. In 1985, R.P. Langlais et al. set up more specific theory based on the earlier scholars[24]. However, the two-dimensional analyzed method limited the observing and classifying the bifurcated mandibular canal. Besides, their method of classification is a little cumbersome for implication. Besides, their method of classification is a little cumbersome for implication. With the adventure of CBCT, Naitoh set up a new classification which could be more convenient to find the BMC[21]. It is more exhaustive and comprehensive than those previous methods with panoramic radiographs, such as its definition for buccal-lingual canal. This theory is more detailed and emphasizes the relationship with molars. But it cannot fully reflect the location of BMC, such as type 3, type 4 . In addition, it is hard to accurately describe the existence of multiple canals and other complicated situations on one side.

At present, different scholars use different classification criteria which may result in many understandings of the classification methods and lead to inconsistent research results. Observers have different levels of understanding of the anatomical variation, and ignore to make the mutual verification of sagittal, coronal, and cross-section, all these can cause different results about the same image, even for the same classification criteria, various types of results may be inconsistent. Besides, the anatomical variations of the mandibular canal in different regions and different races may be inherently various. It may have relationship with congenital variations, lifestyle, chewing habit of some people. Further research is needed to verify whether these habits will lead to different occurrence rates of anatomical variation of mandibular canal.

\subsection{The advantages of our classification theory}

At present, scholars use different classification criteria for BMC because of no consolidated standard, which may result in many inconsistent 
research results. Based on the explicitly defined the boundary of mandibular body and ramus, we made a reclassification of the BMC, and this improved method will help to guide future development of surgery. The classification can record the amount of multi-canal on one side, which is also more comprehensive and useful for other complicated situations. Also, we measured distances between root and inferior alveolar nerve canal and showed the sutures in detail, which can precisely guide surgical correction. Therefore, our method can supply a profound clinical significance for the mandible operation and it is easier for training and academic communication. Furthermore, we pointed a constant site and position for scholars to study BMC, which is stable for different population and more objective for measured data and clinical application.

Nevertheless, we only described the location, amount and other complicated conditions of the bifurcated mandibular canal. But our classification still has limitation in reflecting the general trend of the BMC and information about distance.

\subsection{Clinical implication of $B M C$}

\subsubsection{Block anesthesia and dental extraction of the mandibular impacted molar}

The inferior alveolar nerve block anesthesia is very important for the dental extraction in our clinical operation. However, because of the improper operation and the BMC the success rate of block anesthesia of inferior alveolar nerve is $82 \%-91 \%[25,26]$. Therefore, scholars aimed to the study of the anatomy and pathology of the mandibular bifurcation [1, 8, 12, 27-29]. Some research suggested the mandibular impacted teeth are closely related to the mandibular canal and its branches. Not only can Yamada[30] find the incidence rate of BMC reaching to 94.6\%, but $54.8 \%$ branches contact with the third molar. In another classify method, they categorized into 5 groups about the relationship between bifurcations of mandibular canal and the third molar[31]. But different methods to classify the relationship will have different result, which the 
outcomes from $28 \%$ to $94.6 \%[32]$. For all this, the common bifurcate position of mandibular canal located around the retromolar pad. This is why the ineffective block anesthesia and bleeding appeared in clinical.

In our study, we pay attention to the precision measurement of distance between BMC to molar apical foramen. Our results showed that the average vertical distance from the second molar and third molar to BMC is only $4.36 \pm 2.51 \mathrm{~mm}$ and $2.45 \pm 2.23 \mathrm{~mm}$. Meanwhile the bifurcated site to the root tips is less than $9 \mathrm{~mm}$. That means the blood supply and nerve distribution of molars were upper branch of BMC. This may explain why only a percentage of patients presented ineffective block anesthesia and bleeding even though they all have the same treatment. Therefore, we need to take a CBCT scan for further diagnose and to be gentle during extraction with the BMC patients in clinical practice.

\subsubsection{Applied to implantology}

Implants denture have been normally accepted by clinicians and patients for their excellent ability to restore occlusion and safety for the adjacent teeth. However, each doctor has to consider the trend of MC; otherwise, it will be injured when implant surgery occurs in the mandibular molar and the premolar region. The most important clinical implication of BMC in implantology is to attract the attention of the majority of doctor in implant work. During daily clinical work, most implanters focus on the damage to the mandibular canal rather than bifurcation at mandibular body. In this study, the incidence rate of Type II and Type III bifurcation at mandibular body are respectively $2.57 \%$ and $0.71 \%$. Besides, vertical distance between the apex of the second molar, and mandibular canal is only $4.36 \pm 2.51 \mathrm{~mm}$ and distance from the apex of the second molar to the bifurcated spot are $15.87 \pm 6.82 \mathrm{~mm}$. The direction and depth of implant should follow the guidance of CBCT. This suggests that we must pay attention to these bifurcation at mandibular body. For some unexplained sense disorder, it may be related to injury or compression of BMC. 


\subsubsection{Applied to SSRO and RIF of mandible fracture}

An important complication of sagittal split ramus osteotomy (SSRO) and rigid internal fixation (RIF) of mandible fracture is damage to the inferior alveolar nerve and blood vessels. In this study, Type I account for $14.71 \%$ and Type III for $0.71 \%$, which suggests that there is a high risk of intraoperative injury. In other words, the symptoms of neurological disorders after surgery may be concerned with the damage of bifurcation at mandibular ramus.

\section{Conclusion}

In summary, we retrospectively studied the anatomical variation of the mandibular neural canal by CBCT and summed up a more comprehensive, simple, and practical classification for BMC, which can make clinical work and academic communication easier. The most common is Type I, especially Type $\mathrm{I}_{\mathrm{B}}$, and the least is Type III. Finally, it is important for clinicians to identify this anatomical variation in extraction of mandibular third molar, block anesthesia of inferior alveolar nerve, mandibular molar implantation, and SSRO. Clinician should use $\mathrm{CBCT}$ to identify this structural variation in the risky area, which has important clinical implication for reducing complications.

\section{Abbreviations}

BMC: bifurcated neural canal; CBCT: cone beam computed tomography; SSRO: sagittal split ramus osteotomy; BSSRO: bilateral sagittal split ramus osteotomy; RIF: rigid internal fixation; MC: mandible canal 


\section{Declarations:}

\section{Acknowledgement:}

Not applicable

Author contributions:

All authors have read and approved the manuscript. Contributions to design: Hao Yang, Yue Wu, Kun Li. Acquisition of data: Hao Yang, Yue Wu, Pengyu Hong. Data analysis: Hao Yang, Yue Wu, Yanjia Hu. Drafting of the manuscript: Hao Yang, Yue Wu, Kun Li

Funding:

This work has been supported by, the National Natural Science Foundation of China (82800952), the Natural Science Foundation of Hunan Province, China(2018JJ3712) and the Fundamental Research Funds for the Central Universities of Central South University(2018zzts838). The authors deny any conflicts of interest.

Availability of data and materials:

The datasets used and/or analyzed during the current study are available from the corresponding author on reasonable request.

Ethics approval and consent to participate:

Our study was approved by the Ethical Committee of Xiangya Stomatological Hospital of Central South University, approval number 
20190034.

Consent for publication

Not applicable.

Competing interests:

Each author declares that they have no competing interests.

\section{References:}

1. Schejtman R, Devoto F, Arias N: The origin and distribution of the elements of the human mandibular retromolar canal. Arch Oral Biol 1967, 12(0003-9969 (Print)):1261-1268.

2. Jablonski N, Cheng $\mathrm{C}$, Cheng L, Che ung H: Unusual origins of the buccal and mylohyoid nerves. Oral surgery, oral medicine, oral pathology and oral radiology 1985, 60(0030-4220 (Print)):487-488.

3. Claeys V, Wackens G: Bifid mandibular canal: literature review and case report. Dento maxillo facial radiology 2005, 34(0250-832X (Print)):55-58.

4. Sonneveld KA, Mai PT, Hogge M, Choi EY, Portnof JE: Bifid Mandibular Canal: A Case Review and Retrospective Review of CBCTs. (1538-2982 (Electronic)).

5. Orhan K, Aksoy S, Bilecenoglu B, Sakul B, Paksoy C: Evaluation of bifid mandibular canals with cone-beam computed tomography in a Turkish adult population: a retrospective study. Surg Radiol Anat 2011, 33(1279-8517 (Electronic)):501-507.

6. Carter R, Keen E: The intramandibular course of the inferior alveolar nerve. J Anat 1971, 108(0021-8782 (Print)):433-440.

7. Moiseiwitsch J: Position of the mental foramen in a North American, white population. Oral Surg Oral Med Oral Pathol Oral Radiol Endod 1998, 85(1079-2104 (Print)):457-460.

8. Wadu S, Penhall B, Townsend G: Morphological variability of the human inferior alveolar nerve. Clin Anat 1997, 10(0897-3806 (Print)):82-87.

9. Rouas P, Nancy J, Bar D: Identification of double mandibular canals: literature review and three case reports with CT scans and cone beam CT. Dento maxillo facial radiology 2007, 36(0250-832X (Print)):34-38. 
10. Auluck A, Pai K, Shetty C: Pseudo bifid mandibular canal. Dento maxillo facial radiology 2005, 34(0250-832X (Print)):387-388.

11. Mizbah K, Gerlach N, Maal TJ, Bergé S, Meijer G: The clinical relevance of bifid and trifid mandibular canals. Oral Maxillofac Surg 2012, 16(1865-1569 (Electronic)):147-151.

12. Fukami K, Shiozaki KF, Mishima A, Kuribayashi A, Hamada Y, Kobayashi K: Bifid mandibular canal: confirmation of limited cone beam CT findings by gross anatomical and histological investigations. Dentomaxillofac Radiol 2012, 41(0250-832X (Print)):460-465.

13. Villaça-Carvalho M, Manhães L, Jr, de Moraes M, Lopes S: Prevalence of bifid mandibular canals by cone beam computed tomography. Oral Maxillofac Surg 2016, 20(1865-1569 (Electronic)):289-294.

14. Klinge B, Petersson A, Maly P: Location of the mandibular canal: comparison of macroscopic findings, conventional radiography, and computed tomography. Int J Oral Maxillofac Implants 1989, 4(0882-2786 (Print)):327-332.

15. Sanchis J, Penarrocha M, Soler F: Bifid mandibular canal. J Oral Maxillofac Surg 2003, 61(0278-2391 (Print)):422-424.

16. Kasabah S, Modellel Y: Classification of bifid mandibular canals in the Syrian population using panoramic radiographs. East Mediterr Health J 2014, 19(1020-3397 (Print)):178-183.

17. Kuczynski A, Kucharski W, Franco A, Westphalen F, de L, AA, Fernandes A: Prevalence of bifid mandibular canals in panoramic radiographs: a maxillofacial surgical scope. Surg Radiol Anat 2014, 36(1279-8517 (Electronic)):847-850.

18. Kalantar Motamedi MH, Navi F, Sarabi N: Bifid mandibular canals: prevalence and implications. J Oral Maxillofac Surg 2015, 73(1531-5053 (Electronic)):387-390.

19. Rashsuren O, Choi J, Han W, Kim E: Assessment of bifid and trifid mandibular canals using cone-beam computed tomography. Imaging Sci Dent 2014, 44(2233-7822 (Print)):229-236.

20. Kang JH, Lee KS, Oh MG, Choi HY, Lee SR, Oh SH, Choi YJ, Kim GT, Choi YS, Hwang EH: The incidence and configuration of the bifid mandibular canal in Koreans by using cone-beam computed tomography. Imaging Sci Dent 2014, 44(2233-7822 (Print)):53-60.

21. Naitoh M, Hiraiwa Y, Aimiya H, Ariji E: Observation of bifid mandibular canal using cone-beam computerized tomography. Int $J$ Oral Maxillofac Implants 2009, 24(0882-2786 (Print)):155-159.

22. Zhang YQ, Zhao YN, Liu DG, Meng Y, Ma XC: Bifid variations of the mandibular canal: cone beam computed tomography evaluation of 1000 Northern Chinese patients. Oral surgery, oral medicine, oral pathology and oral radiology 2018, 126(5):e271-e278.

23. Nortjé C, Farman A, Grotepass F: Variations in the normal anatomy of the inferior dental (mandibular) canal: a retrospective study of panoramic radiographs from 3612 routine dental patients. Br J Oral Surg 1977, 15(0007-117X (Print)):55-63. 
24. Langlais R, Broadus R, Glass B: Bifid mandibular canals in panoramic radiographs. J Am Dent Assoc 1985, 110(0002-8177 (Print)):923-926.

25. Kikuta S, Iwanaga J, Nakamura K, Hino K, Nakamura M, Kusukawa J: The retromolar canals and foramina: radiographic observation and application to oral surgery. Surg Radiol Anat 2018, 40(1279-8517 (Electronic)):647-652.

26. Lew K, Townsen G: Failure to obtain adequate anaesthesia associated with a bifid mandibular canal: a case report. Aust Dent $J 2006$, 51(0045-0421 (Print)):86-90.

27. Haghighat A, Jafari ZF, Hasheminia D, Samandari M, Safarian V, Davoudi A: Comparison of success rate and onset time of two different anesthesia techniques. Med Oral Patol Oral Cir Bucal 2015, 20(1698-6946 (Electronic)):e459-463.

28. Bilecenoglu B, Tuncer N: Clinical and anatomical study of retromolar foramen and canal. J Oral Maxillofac Surg 2006, 64(0278-2391 (Print)):1493-1497.

29. Singh S: Aberrant buccal nerve encountered at third molar surgery. Oral Surg Oral Med Oral Pathol Oral Radiol Endod 1981, 52(0030-4220 (Print)): 142 .

30. Yamada T, Ishihama K, Yasuda K, Hasumi-Nakayama Y, Ito K, Yamaoka M, Furusawa K: Inferior alveolar nerve canal and branches detected with dental cone beam computed tomography in lower third molar region. J Oral Maxillofac Surg 2011, 69(1531-5053 (Electronic)):1278-1282.

31. de O-S, C, Souza P, de A, Berti-Couto,S, Stinkens L, Moyaert K, Rubira-Bullen I, Jacobs R: Assessment of variations of the mandibular canal through cone beam computed tomography. Clin Oral Investig 2012, 16(1436-3771 (Electronic)):387-393.

32. Correr G, Iwanko D, Leonardi D, Ulbrich L, Araujo M, Deliberador T: Classification of bifid mandibular canals using cone beam computed tomography. Braz Oral Res 2013, 27(1807-3107 (Electronic)):510-516. 


\section{Tables :}

Tab.1 New classification of bifurcated mandibular canal

\begin{tabular}{|l|l|l|}
\hline \multirow{2}{*}{ I } & IA & A bifurcation at the mandibular ramus and the retromolar foramen has been formed. (Fig. 2A; Note 1) \\
\cline { 2 - 3 } & IB & A bifurcation at the mandibular ramus and the retromolar foramen has not been formed. (Fig. 2B) \\
\hline II & Bifurcations at the mandibular body. (Fig. 2C) \\
\hline III & Bifurcations exist both at the mandibular body and the mandibular ramus on one side. (Fig. 2D, E; Note 2) \\
\hline IV & Other circumstances (e.g., trigeminal nerve canal or multi-canal derived from different origins) (Fig. 2F) \\
\hline
\end{tabular}

Tab.2.1350 samples of bifurcations in male and female mandibular canals

\begin{tabular}{|l|l|l|l|l|}
\hline & Yes & No & Amount & Incidence rate (\%) \\
\hline Male & 32 & 88 & 120 & 26.67 \\
\hline Female & 78 & 152 & 230 & 33.91 \\
\hline Amount & 110 & 240 & 350 & 31.43 \\
\hline
\end{tabular}

Tab 2.2 The appearance of different position of BMCs 


\begin{tabular}{|l|l|l|l|}
\hline & Left & Right & Total \\
\hline Male & 13 & 25 & 38 \\
\hline Female & 46 & 49 & 95 \\
\hline Total & 59 & 74 & 133 \\
\hline
\end{tabular}

Tab 2.3 The appearance of unilateral or bilateral BMCs

\begin{tabular}{|l|l|l|l|}
\hline & Unilateral & Bilateral & Total \\
\hline Male & 31 & 7 & 38 \\
\hline Female & 78 & 17 & 95 \\
\hline Total & 109 & 24 & 133 \\
\hline
\end{tabular}

Tab.3 Each type of BMC's incidence rate, $n=700$

\begin{tabular}{|c|c|c|c|c|c|c|}
\hline \multicolumn{2}{|c|}{} & Male & Female & \multicolumn{2}{c|}{ Amount } & \\
\hline \multirow{2}{*}{ I } & IA & 7 & 20 & 27 & 3.86 & 14.71 \\
\cline { 2 - 6 } & IB & 24 & 52 & 76 & 10.86 & 0.71 \\
\hline II & 5 & 13 & 18 & 1.00 \\
\hline III & 0 & 5 & 5 & & 19.00 \\
\hline IV & 2 & 5 & 133 & & \\
\hline Amount & 38 & 95 & & & \\
\hline
\end{tabular}


Tab.4 Distance between two molar and anatomic site in Type I and Type II (mean \pm SD)

\begin{tabular}{|l|l|l|l|}
\hline & $\begin{array}{l}\text { Vertical distance } \\
(\mathrm{mm})\end{array}$ & $\begin{array}{l}\text { Bifurcated site } \\
(\mathrm{mm})\end{array}$ & $\begin{array}{l}\text { Retromolar foramen } \\
(\mathrm{mm})\end{array}$ \\
\hline The second molar & $4.36 \pm 2.51$ & $15.87 \pm 6.82$ & $22.19 \pm 5.97$ \\
\hline The third molar & $2.45 \pm 2.23$ & $9.32 \pm 5.37$ & $15.82 \pm 4.68$ \\
\hline
\end{tabular}

Tab.5 Difference between four theories

\begin{tabular}{|c|c|c|c|c|c|c|c|}
\hline Methods & Basis of classification & Tool & $\begin{array}{l}\text { Dimensions } \\
\text { of image } \\
(2 \mathrm{D} / 3 \mathrm{D})\end{array}$ & Category & $\begin{array}{l}\text { Comprehensive } \\
\text { coverage }\end{array}$ & Measured data & Incidence rate \\
\hline $\begin{array}{l}\text { Nortje et } \\
\text { al. }\end{array}$ & $\begin{array}{l}\text { The height of the mandibular } \\
\text { canal in the mandible. }\end{array}$ & $\begin{array}{l}\text { Orthopan } \\
\text { tomogra } \\
\text { phy }\end{array}$ & $2 \mathrm{D}$ & 4 & Position & None & $\begin{array}{l}46.7 \% \\
(1685 / 3612) \\
\text { Male:48.9\% } \\
\text { Female:45.7\% }\end{array}$ \\
\hline $\begin{array}{l}\text { Langlais } \\
\text { et al. }\end{array}$ & $\begin{array}{l}\text { Unilateral bifurcation or } \\
\text { bilateral and the relationship of } \\
\text { convergence between } \\
\text { bifurcation and the canal. }\end{array}$ & $\begin{array}{l}\text { Orthopan } \\
\text { tomogra } \\
\text { phy }\end{array}$ & $2 \mathrm{D}$ & 4 & $\begin{array}{l}\text { Unilateral or } \\
\text { bilateral }\end{array}$ & none & $\begin{array}{l}\text { Male:39\%; } \\
\text { Female: } 61 \%\end{array}$ \\
\hline $\begin{array}{l}\text { Naitoh et } \\
\text { al. }\end{array}$ & Directions of the canal. & $\mathrm{CBCT}$ & $3 \mathrm{D}$ & 4 & Direction & $\begin{array}{l}\text { The length of } \\
\text { BMC: I: } 14.8 ; \\
\text { II: } 8.9 ; \quad \text { III: } 8.6 ; \\
\text { IV: } 1.6\end{array}$ & $65 \%(125)$ \\
\hline Author & relationship & $\mathrm{CBCT}$ & $3 \mathrm{D}$ & 4 & Position & distance & Male: $22.67 \%$ \\
\hline
\end{tabular}




\begin{tabular}{|l|l|l|l|l|l|l|}
\hline $\begin{array}{l}\text { of this } \\
\text { article }\end{array}$ & mandibular body and ramus. & & & & distance & $\begin{array}{l}\text { between apex of } \\
\text { molars Female:33.91 } \\
\text { mandibular } \\
\text { and } \\
\text { canal. }\end{array}$ \\
\hline
\end{tabular}

\section{Figure Legend :}

Fig.1 Image-reading position. (1) a horizontal line was made parallel to the lower edge of the mandible (grey line); (2) a tangent line of the front edge of the mandibular ramus (green line), which intersects with the upper edge of the mandibular body (Fig. 1, red circle); (3) a line across the intersection was made vertical to the line in (1) (Fig. 1, yellow line). We defined the following: the bifurcation that appears in front of this vertical line (yellow line) is classified into mandibular body area, whereas the bifurcation that appears behind it is the mandibular ramus area (Fig. 1).

Fig.2 New classification of BMC: The red arrow points to the bifurcations, and the yellow arrow points to the mandibular canal. (A) Type $\mathrm{I}_{\mathrm{A}}$ : Bifurcations at the mandibular ramus, and retromolar foramen has been formed. (B) Type $\mathrm{I}_{\mathrm{B}}$ : Bifurcations at the mandibular ramus, and retromolar foramen has not been formed. (C) Type II: Bifurcations at the mandibular body. (D)-(F) Type III: Bifurcations exist both at the mandibular body and the mandibular ramus on one side. (G) Type IV: Other circumstances. 


\section{Figures}

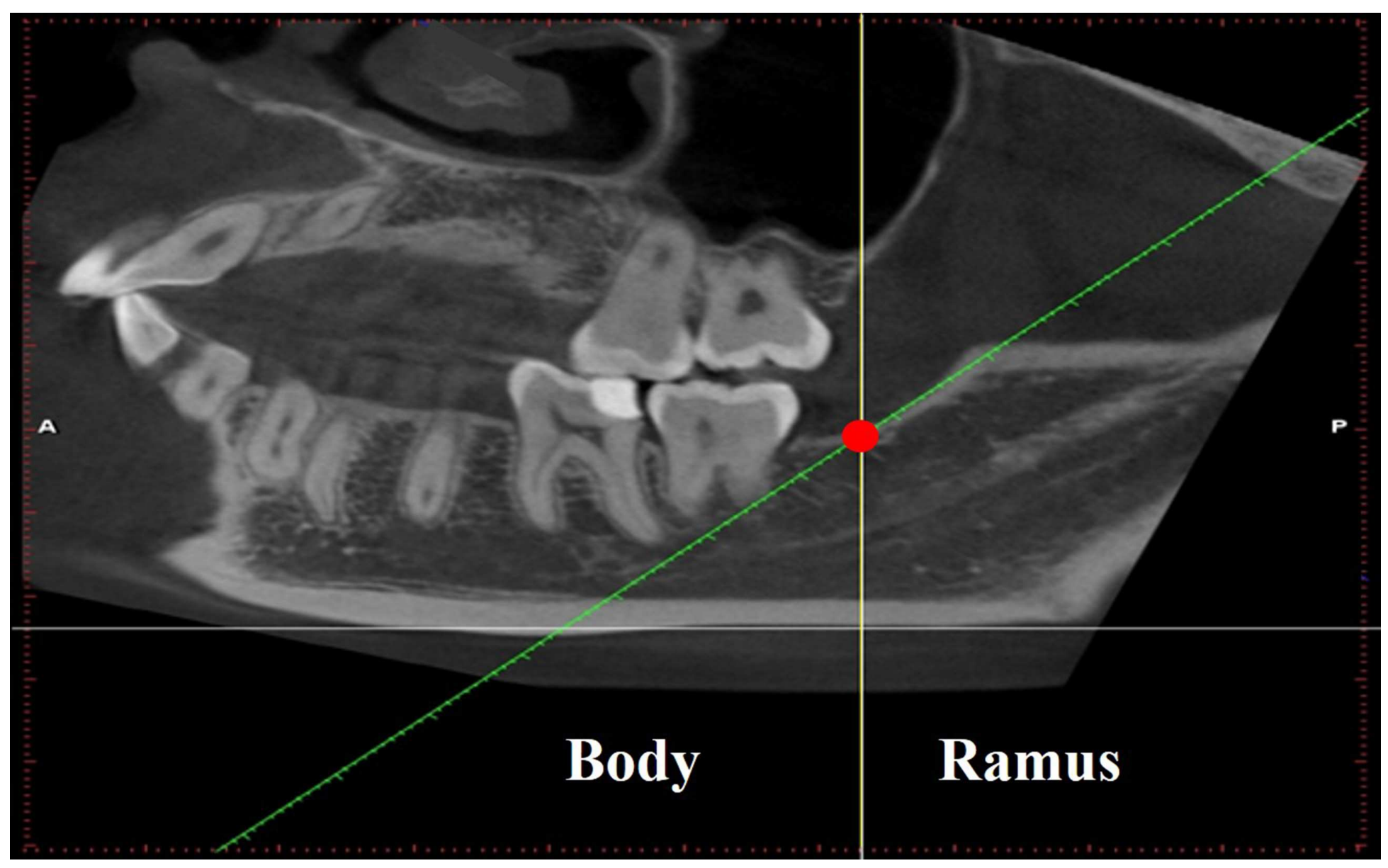

\section{Figure 1}

Image-reading position. (1) a horizontal line was made parallel to the lower edge of the mandible (grey line); (2) a tangent line of the front edge of the mandibular ramus (green line), which intersects with the upper edge of the mandibular body (Fig. 1, red circle); (3) a line across the intersection was made vertical to the line in (1) (Fig. 1, yellow line). We defined the following: the bifurcation that appears in front of this vertical line (yellow line) is classified into mandibular body area, whereas the bifurcation that appears behind it is the mandibular ramus area (Fig. 1). 

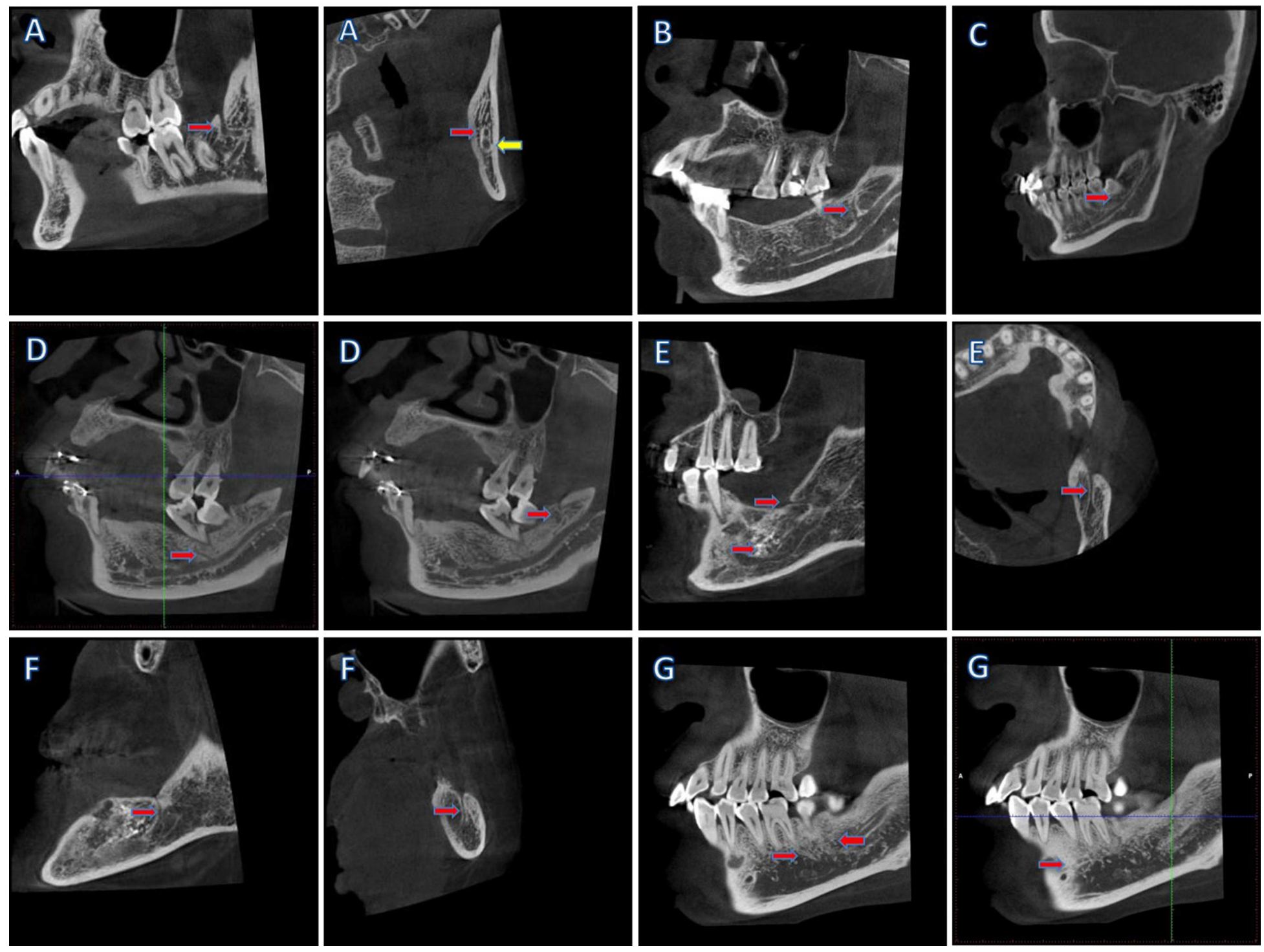

Figure 2

New classification of BMC: The red arrow points to the bifurcations, and the yellow arrow points to the mandibular canal. (A) Type IA: Bifurcations at the mandibular ramus, and retromolar foramen has been formed. (B) Type IB: Bifurcations at the mandibular ramus, and retromolar foramen has not been formed. (C) Type II: Bifurcations at the mandibular body. (D)-(F) Type III: Bifurcations exist both at the mandibular body and the mandibular ramus on one side. (G) Type IV: Other circumstances.

\section{Supplementary Files}

This is a list of supplementary files associated with this preprint. Click to download.

- Tab.2.pdf

- Tab.1.pdf

- Tab.3.pdf 
- Tab.4.pdf

- Tab.5.pdf 